\title{
Isolation and structural determination of a new macrolide, makinolide, from the newly isolated Streptomyces sp. MK-30
}

\author{
Shinya Kodani ${ }^{1,2}$, Ayako Murao ${ }^{3}$, Michitaka Hidaki ${ }^{1}$, Kanna Sato ${ }^{1}$ and Naoto Ogawa ${ }^{3}$ \\ The Journal of Antibiotics (2012) 65, 331-334; doi:10.1038/ja.2012.24; published online 11 April 2012
}

Keywords: anti-yeast compound; macrolide; NMR spectrum; Streptomyces

Macrolides are a group of organic compounds that possess a macrolide ring (usually 14-, 15- or 16-membered) as the carbon skeleton. Most of the isolated macrolides are structurally diverse antibiotics such as erythromycin ${ }^{1,2}$ and are produced by microorganisms such as the soil-dwelling bacterium Streptomyces via polyketide biosynthesis. ${ }^{3}$ They exhibit various biological activities, including antitumor, antifungal, antiparasitic and immunosuppressant activities. Among the macrolides, bafilomycins ${ }^{4,5}$ and setamycin ${ }^{6,7}$ are 16 -membered macrolides that are reported to exhibit specific membrane ATPase inhibitory activity. ${ }^{8}$ In the course of screening for anti-yeast compounds, we isolated a new bafilomycin analog named makinolide ( $\mathbf{1}$ in Figure 1a), along with the known macrolide JBIR - 100 ( 2 in Figure $1 \mathrm{a})^{9,10}$ from newly isolated strain, Streptomyces sp. MK-30. Herein, we describe the isolation and structural determination of makinolide (1).

The new bacterial strain MK-30 was isolated from the soil of a tea field (Makinohara, Shizuoka, Japan) along with 32 other bacterial strains using ISP2 agar medium. With the aim of screening for antiyeast compounds, these strains were cultured with ISP2 agar media for 7 days. The spent culture media were extracted with acetone. Then, each acetone extract was subjected to anti-yeast activity screening against Saccharomyces cerevisiae (NBRC2376), and the strain MK-30 was found to produce a significant amount of anti-yeast substances.

To identify the genetic position of the MK-30 strain, sequencing analysis was performed on the $16 \mathrm{~S}$ ribosomal RNA (rRNA) coding gene. Using a typical polymerase chain reaction (PCR) method with universal primers for the bacterial $16 \mathrm{~S}$ rRNA gene, the nearly complete length of the 16S rRNA gene was amplified. The sequence analysis was accomplished using an automated DNA sequencer with eight universal primers. From the obtained sequence, a phylogenetic tree was constructed using the multiple-alignment program ClustalX. It was determined that the genetic position of MK-30 is located in the genus Streptomyces (Supplementary Figure S1). The strain MK-30 is closely related to Streptomyces sahachiroi, with a high similarity of $99 \%$. The $16 \mathrm{~S}$ rDNA sequence of Streptomyces sp. MK-30 was deposited in the DDBJ database under the accession number AB691771.

To isolate the anti-yeast compounds, the cultivation of the strain MK-30 was performed with 11 of ISP2 agar media. After 7 days of cultivation, the spent agar culture media were extracted with an equal volume of acetone. After concentration, the acetone extract was subjected to open column chromatography using the synthetic hydrophobic resin $\mathrm{CHP}-20 \mathrm{P}$ and eluted with $20 \% \mathrm{MeOH}, 60 \%$ $\mathrm{MeOH}$ and then $\mathrm{MeOH}$. As the $\mathrm{MeOH}$ fraction showed potent activity, the $\mathrm{MeOH}$ fraction was repeatedly subjected to preparatory HPLC to yield the new macrolide makinolide $(1,3.3 \mathrm{mg})$ and the known macrolide JBIR - 100 (2, $2.0 \mathrm{mg}$ ).

Makinolide was isolated as a white amorphous powder. HR-ESIMS analysis of 1 gave an $[\mathrm{M}+\mathrm{Na}]^{+}$ion at $m / z$ 822.44272, consistent with the molecular formula $\mathrm{C}_{44} \mathrm{H}_{65} \mathrm{NO}_{12}$ (calculated $[\mathrm{M}+\mathrm{Na}]^{+}$ion at $m / z$ 822.44044). To obtain further information on the chemical structure, NMR experiments including ${ }^{1} \mathrm{H}, \mathrm{HMQC}, \mathrm{HMBC}, \mathrm{DQF}-$ COSY and TOCSY analyses of 1 were performed in acetone $-d_{6}$ (Supplementary Figures S2-S7).

The direct bonds between each proton and carbon were established in the HMQC spectrum (Table 1). As shown by the bold line in Figure 1b, the analysis of the TOCSY and DQF-COSY spectra revealed proton-proton spin connections in five partial structures: carbon skeletons connecting $\mathrm{C} 5$ to $\mathrm{C} 9, \mathrm{C} 11$ to $\mathrm{C} 18, \mathrm{C} 20$ to $\mathrm{C} 25, \mathrm{C} 2{ }^{\prime}$ to $\mathrm{C} 3^{\prime}$ and $\mathrm{C}^{\prime}$ to $\mathrm{C}^{\prime}$. The HMBC correlations between the protons of the 2-Me group and C1, C2 and C3, and between the protons of the 4-Me group and $\mathrm{C} 3, \mathrm{C} 4$ and $\mathrm{C} 5$, indicated a 2, 4-dimethyl dienone structure. The HMBC correlations between the protons of the 10-Me group and C9, C10 and C11 indicated a connection between the (C5 to C9) and (C11 to C18) partial structures. The HMBC correlations between the protons of the 18-Me group, $\mathrm{H} 18, \mathrm{H} 20$ and $\mathrm{C} 19$ indicated a hemiacetal structure, which was also confirmed by the characteristic 


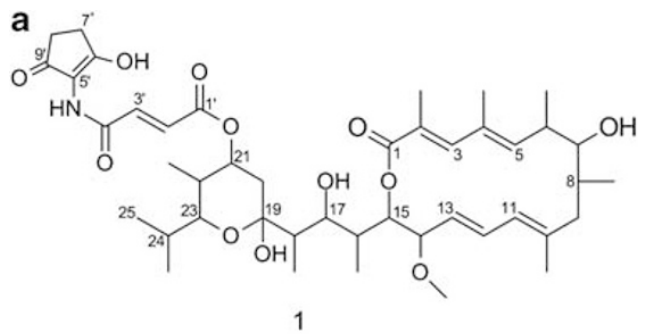<smiles>COC(/C=C/C=C(\C)CC(C)C(O)C(C)/C=C(C)/C=C(\C)C(=O)OC(C(C)C)C(C)C(O)C(C)C1(O)CC(OC(=O)/C=C/C(=O)O)C(C)C(C(C)C)O1)C(C)C</smiles>

b

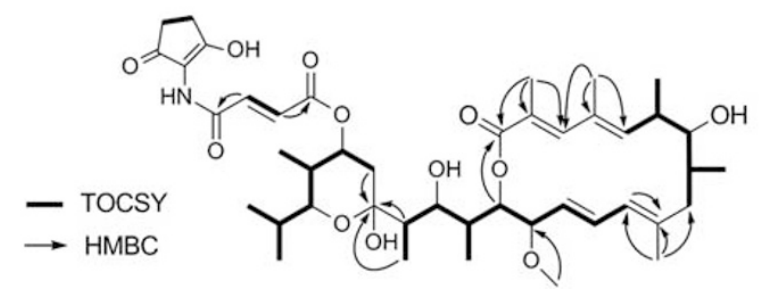

Figure 1 (a) Chemical structure of makinolide (1) and JBIR-100 (2). (b) Selected NMR correlations of 1.

chemical shift value for C19 ( $\delta c$ 99.4). The HMBC correlation between $\mathrm{H} 23$ and $\mathrm{C} 19$ was not observed; however, a comparison of the chemical shift values with the related compound JBIR -100 confirmed the cyclic hemiacetal moiety. The presence of the $\mathrm{N}$-(3hydroxy-2-cyclopentenone-2-yl)-fumaric acid monoamide moiety $\left(\mathrm{Cl}^{\prime}-\mathrm{C}^{\prime}\right)$ was confirmed by the chemical shifts observed in the HMQC spectrum and the molecular formula determined by the HRESI-MS analysis. Although no HMBC correlations were observed between $\mathrm{H}^{\prime}$ and $\mathrm{H}^{\prime}$, the similarity of the chemical shift values for the $7^{\prime}$ and $8^{\prime}$ positions to the values for these positions in the related compound R176502 $2^{11}$ support the structural assignment. Previously, the acid hydrolysis of bafilomycin B1 was reported to form $\mathrm{N}$-(3hydroxy-2-cyclopentenone-2-yl)-fumaric acid monoamide. ${ }^{12}$ To confirm the partial structure containing the $N$-(3-hydroxy-2cyclopentenone-2-yl)-fumaric acid monoamide moiety $\left(\mathrm{C1}^{\prime}-\mathrm{C}^{\prime}\right)$, mild acid hydrolysis of $\mathbf{1}$ was accomplished following the procedure described in the previous report. ${ }^{12}$ The chemical shifts in the ${ }^{1} \mathrm{H}$ NMR spectrum (in $\mathrm{MeOH}-d_{4}$ ) of the obtained compound were identical to those observed in the spectrum of $N-(3-$ hydroxy -2 cyclopentenone-2-yl)-fumaric acid monoamide derived from an authentic sample of bafilomycin B1, which confirmed the partial structure of the $\mathrm{C1}^{\prime}-\mathrm{C7}^{\prime}$ skeleton (Supplementary Figures S8 and S9).

In the disc difussion assay, the sensitivity of various microorganisms was tested against macrolides $\mathbf{1}$ and $\mathbf{2}$ following previously reported procedures (Table 2). ${ }^{4}$ Among the bacteria, compounds 1 and $\mathbf{2}$ showed inhibitory activities only against Micrococcus luteus at the doses of 15 and $50 \mu \mathrm{g}$ per disc. Bafilomycins have been reported to be specific inhibitors of the membrane ATPase of eucaryotic cells, ${ }^{8}$ and recently, 2 was confirmed to exhibit inhibitory activity against vacuolar-type ATPase. ${ }^{9}$ Considering the inhibitory mechanism of bafilomycins, the related compounds $\mathbf{1}$ and $\mathbf{2}$ were thought to be active against yeast and fungi; however, among the six strains of yeast and fungi that were tested, macrolides $\mathbf{1}$ and $\mathbf{2}$ exhibited inhibitory activities against only $S$. cerevisiae and Mucor hiemalis (Table 2).

\section{EXPERIMENTAL PROCEDURE}

\section{General Methods}

NMR spectra were obtained using a JEOL ECA-600 in acetone- $d_{6}$ or MeOH- $d_{4}$ (JEOL Ltd, Tokyo, Japan) at $27.0^{\circ} \mathrm{C}$. The ESI-MS spectrum was recorded using a JEOL JMS-T100LP mass spectrometer.

\section{PCR amplification, sequencing and phylogenetic analysis of $16 \mathrm{~S}$ rRNA genes}

The extraction of all DNA from the cells of the strain MK-30 was performed according to the literature procedure. ${ }^{13}$ The $16 \mathrm{~S}$ rRNA-encoding sequence was amplified from the total DNA by the PCR method with two sets of universal primer pairs: 9F (5'-GAGTTTGATCCTGGCTCAG-3') and 926R (5'-CCG TCAATTCCTTTGAGTTT-3'); and 686F (5'-TAGCGGTGAAATGCGTAGA- $3^{\prime}$ ) and 1510R $\left(5^{\prime}\right.$-GGCTACCTTGTTACGA- $\left.3^{\prime}\right)$. For PCR, the reaction mixture was prepared by adding $1.0 \mu \mathrm{l}$ of the total DNA of the MK-30 strain (100 ng), $1.0 \mu \mathrm{l}$ of Pfu DNA polymerase (Bioneer, Daejeon, South Korea), $5.0 \mu \mathrm{l}$ of X10 reaction buffer (Bioneer), $4 \mu \mathrm{l}$ of $2.5 \mathrm{~mm}$ dNTP mix solution (Bioneer) and $31 \mu \mathrm{l}$ of distilled water into the PCR reaction tube. PCR amplification was carried out using a thermal cycler using the following program: initial denaturation for $10 \mathrm{~min}$ at $94^{\circ} \mathrm{C}$, followed by 34 cycles consisting of denaturation for $40 \mathrm{~s}$ at $94^{\circ} \mathrm{C}$, annealing for $60 \mathrm{~s}$ at $55^{\circ} \mathrm{C}$ and DNA synthesis for $1 \mathrm{~min}$ at $72{ }^{\circ} \mathrm{C}$. A final extension of $5 \mathrm{~min}$ at $72{ }^{\circ} \mathrm{C}$ was included at the end of the 34 cycles. The PCR product was purified with a Qiagen PCR PURE kit (Qiagen, Venlo, Netherlands) following the manufacturer's instructions. The reactions for sequencing were performed using a Beckman DTCS-Quick Start Kit following the manufacturer's instructions. Four primers were used for the reaction: 339F $\left(5^{\prime}-\mathrm{CTCC}\right.$ TACGGGTGAGTAACAC- $\left.3^{\prime}\right)$, 536R (5'-GTATTACCGCGG CTGCTG-3'), 686F (5'-TAGCGGTGAAATGCGTAGA- $\left.3^{\prime}\right)$ and 1099F (5'-GCAACGAGCGC AACCC- $\left.3^{\prime}\right)$. The sequencing was performed with the capillary DNA sequencer CEQ8000XL (Beckman Coulter, Brea, CA, USA).

\section{Isolation of the bacterial strains}

The soil samples were collected from a tea-field ground in Makinohara, Shizuoka, Japan. The soil samples were spread onto ISP2 agar medium. After 4-5 days of incubation at $30^{\circ} \mathrm{C}$, the colonies that developed were isolated and stored in a refrigerator at $-80^{\circ} \mathrm{C}$. In total, 33 strains were collected and cultured for anti-yeast compound screening. Briefly, the ISP agar culture $(25 \mathrm{ml})$ of each strain was extracted with an equal volume of acetone. Each acetone extract was evaporated and dissolved in dimethyl sulfoxide to adjust the concentration to $10 \mathrm{mg} \mathrm{ml}^{-1}$. The anti-yeast activity was evaluated by determining the inhibitory zone that was caused by a $10-\mu \mathrm{g}$ inoculation of the acetone extract sample on a culture of the yeast $S$. cerevisiae using ISP2 agar medium.

\section{Isolation of makinolide}

ISP2 agar medium (11) was used for culturing Streptomyces sp. MK-30. After 7 days at $30^{\circ} \mathrm{C}$, an equal volume of acetone was added to the agar culture for extraction. The acetone extract was concentrated to an aqueous suspension, 
Table 1 NMR chemical shift values of makinolide (1) in acetone- $d_{6}$

\begin{tabular}{|c|c|c|}
\hline Position & $\delta_{\mathrm{C}}$ & $\delta_{\mathrm{H}}(J$ in $\mathrm{Hz})$ \\
\hline 1 & 174.0 & \\
\hline 2 & 121.3 & \\
\hline $2-\mathrm{CH} 3$ & 13.5 & $2.02(\mathrm{~s})$ \\
\hline 3 & 147.9 & 7.25 (s) \\
\hline 4 & 134.0 & \\
\hline $4-\mathrm{CH} 3$ & 15.4 & $1.96(\mathrm{~s})$ \\
\hline 5 & 148.4 & $6.04(d, 9.0)$ \\
\hline 6 & 38.0 & $2.56(\mathrm{~m})$ \\
\hline $6-\mathrm{CH} 3$ & 17.5 & $1.03(\mathrm{~d}, 6.9)$ \\
\hline 7 & 81.0 & $3.29(\mathrm{~m})$ \\
\hline 8 & 39.0 & $1.89(\mathrm{~s})$ \\
\hline $8-\mathrm{CH} 3$ & 22.4 & $0.90(d, 6.9)$ \\
\hline 9 & 43.0 & $1.73(\mathrm{~m})$ \\
\hline 10 & 145.5 & \\
\hline $10-\mathrm{CH} 3$ & 20.2 & $1.90(\mathrm{~s})$ \\
\hline 11 & 125.0 & $5.77(d, 11.0)$ \\
\hline 12 & 134.0 & $6.67(\mathrm{~d}, 15.1,10.3)$ \\
\hline 13 & 127.0 & $5.12(d d, 15.1,9.6)$ \\
\hline 14 & 84.0 & $4.07(\mathrm{~m})$ \\
\hline $14-\mathrm{OCH} 3$ & 56.0 & $3.20(\mathrm{~s})$ \\
\hline 15 & 77.0 & $4.91(\mathrm{~m})$ \\
\hline 16 & 38.0 & $2.08(\mathrm{~m})$ \\
\hline $16-\mathrm{CH} 3$ & 12.5 & $0.83(d, 6.8)$ \\
\hline 17 & 72.0 & $4.10(\mathrm{~m})$ \\
\hline 18 & 42.8 & $1.80(\mathrm{~m})$ \\
\hline $18-\mathrm{CH} 3$ & 24.0 & $0.96(d, 7.6)$ \\
\hline 19 & 99.4 & \\
\hline 20 & 40.5 & $1.26(\mathrm{~m}), 2.31(\mathrm{dd}, 11.5,4.8)$ \\
\hline 21 & 76.0 & $5.01(\mathrm{~m})$ \\
\hline 22 & 38.2 & $1.60(\mathrm{~m})$ \\
\hline 22-CH3 & 22.6 & $0.84(d, 6.9)$ \\
\hline 23 & 75.2 & $3.59(\mathrm{dd}, 10.3,2.1)$ \\
\hline 24 & 28.5 & $1.91(\mathrm{~m})$ \\
\hline 25 & 21.7 & $0.92(d, 6.9)$ \\
\hline 26 & 14.8 & $0.77(d, 6.9)$ \\
\hline $1^{\prime}$ & 164.9 & \\
\hline $2^{\prime}$ & 130.2 & $7.52(d, 15.1)$ \\
\hline $3^{\prime}$ & 135.0 & $6.80(d, 15.1)$ \\
\hline $4^{\prime}$ & 166.9 & \\
\hline $5^{\prime}$ & - & \\
\hline $6^{\prime}$ & - & \\
\hline 7 & 36.3 & $2.76(\mathrm{br})$ \\
\hline $8^{\prime}$ & 26.4 & $2.44(\mathrm{br})$ \\
\hline $9^{\prime}$ & - & \\
\hline
\end{tabular}

which was subjected to an open column chromatography (Mitsubishi Chemical, Tokyo, Japan, CHP20P, $3 \times 5 \mathrm{~cm}$ ), eluting with $50 \mathrm{ml}$ each of $20 \%$ $\mathrm{MeOH}, 60 \% \mathrm{MeOH}$ and $\mathrm{MeOH}$. The $\mathrm{MeOH}$ fraction was subjected to reversephase HPLC using an ODS column (Nacalai Tesque, Kyoto, Japan, Cosmosil C18-MSII $4.6 \times 250 \mathrm{~mm}$ ) with an isocratic elution of $85 \% \mathrm{MeCN}$ containing $0.05 \%$ trifluoroacetic acid (TFA) at an absorbance of $220 \mathrm{~nm}$ to yield makinolide $(1,3.3 \mathrm{mg})$ and JBIR $-100(2,2.0 \mathrm{mg})$.

\section{Mild acid hydrolysis}

To obtain $N$-(3-hydroxy-2-cyclopentenone-2-yl)-fumaric acid monoamide, mild acid hydrolysis was performed. Makinolide $(1.0 \mathrm{mg})$ or authentic bafilomycin B1 (1.0 mg, purchased from Wako, Japan) was dissolved in concentrated TFA and incubated at $80^{\circ} \mathrm{C}$ for $16 \mathrm{~h}$. After evapotation of TFA, $1 \mathrm{ml}$ of distilled water was added. The hydrolysate solution was subjected to reverse-phase HPLC using an ODS column (Nacalai Tesque, Cosmosil MSII
Table 2 Antimicrobial activities of 1 and 2

\begin{tabular}{|c|c|c|c|c|}
\hline \multirow[b]{3}{*}{ Microorganisms } & \multicolumn{4}{|c|}{ Diameter of inhibition zone $(\mathrm{mm})$} \\
\hline & \multicolumn{2}{|c|}{1} & \multicolumn{2}{|c|}{2} \\
\hline & $15 \mu \mathrm{g}$ & $50 \mu \mathrm{g}$ & $15 \mu \mathrm{g}$ & $50 \mu \mathrm{g}$ \\
\hline$<$ Bateria $>$ & - & - & - & - \\
\hline Escherichia coli (NBRC 1002203) & - & - & - & - \\
\hline Pseudomonas aeruginosa (NBRC 12689) & - & - & - & - \\
\hline Serratia marcescens (NBRC 1002204) & - & - & - & - \\
\hline Vibrio harveyi (NBRC 15634) & - & - & - & - \\
\hline Bacillus subtilis (NBRC13719) & - & - & - & - \\
\hline Staphylococcus aureus (NBRC 1009110) & - & - & - & - \\
\hline Micrococcus luteus (NBRC3333) & 15 & 18 & 13 & 20 \\
\hline $\begin{array}{l}\text { Streptomyces antibioticus (NBRC 3117) } \\
<\text { Yeast }>\end{array}$ & - & - & - & - \\
\hline Saccharomyces cerevisiae (NBRC2376) & 12 & 13 & 11 & 9 \\
\hline Schizosaccharomyces pombe (NBRC 0340) & - & - & - & - \\
\hline Kloeckera apiculata (NBRC 0154) & - & - & - & - \\
\hline$<$ Fungi $>$ & & & & \\
\hline Aspergillus niger (NBRC 33023 ) & - & - & - & - \\
\hline Aspergillus oryzae (NBRC 4290) & - & - & - & - \\
\hline Mucor hiemalis (NBRC 9405) & 15 & 18 & 11 & 12 \\
\hline
\end{tabular}

Paper discs (i.d. $6 \mathrm{~mm}$ for $15 \mu \mathrm{g}$ per disc and i.d. $8 \mathrm{~mm}$ for $50 \mu \mathrm{g}$ per disc) were used. The minus (-) means no inhibition.

$4.6 \times 250 \mathrm{~mm}$ ) using isocratic elution of $13 \% \mathrm{MeCN}$ containing $0.05 \%$ TFA and a UV detector set at an absorbance of $220 \mathrm{~nm}$ to yield $\mathrm{N}$-(3-hydroxy-2cyclopentenone-2-yl)-fumaric acid monoamide: HR ESI-MS showed an ion peak at $\mathrm{m} / z 234.0383[\mathrm{M}+\mathrm{Na}]^{+}$calculated for $\mathrm{C}_{9} \mathrm{H}_{9} \mathrm{O}_{5} \mathrm{Na}(\Delta 0.55 \mathrm{mmu})$. The ${ }^{1} \mathrm{H}$-NMR signals $\left(\mathrm{MeOH}-d_{4}\right)$ were detected at $d_{\mathrm{H}} \mathrm{H} 2^{\prime}: 7.18(\mathrm{~d}, 15.1 \mathrm{~Hz}$, $1 \mathrm{H}), \mathrm{H}^{\prime}$ : $6.81(\mathrm{~d}, 15.1 \mathrm{~Hz}, 1 \mathrm{H})$, and $\mathrm{H}^{\prime}$ and $\mathrm{H}^{\prime}$ : $2.54(\mathrm{~s}, 4 \mathrm{H})$.

Bacterial strains for antimicrobial assay

All microorganisms shown in Table 1 were obtained from the NBRC culture collection (NITE Biological Resource Center, Kisarazu, Japan). Cultivation was performed using ISP2 liquid medium at $37^{\circ} \mathrm{C}$ for $24 \mathrm{~h}$. The disc diffusion assay using a paper disc (i.d. $6 \mathrm{~mm}$, thin type for $15 \mu \mathrm{g}$; and i.d. $8 \mathrm{~mm}$, thick type for $50 \mu \mathrm{g}$ ) was performed to determine the antimicrobial activity of $\mathbf{1}$ and 2.

\section{ACKNOWLEDGEMENTS}

This study was supported by research funds from the Takeda Science Foundation, the Astellas Foundation for Research on Metabolic Disorders, the Foundation of Hattori Hokokai and The Kurata Memorial Hitachi Science and Technology Foundation. We appreciate Mr Hidemi Nagata for providing the soil samples.

1 Demarco, P. V. NMR study of some erythromycin aglycones. A conformational and configurational analysis. J. Antibiot. 22, 327-340 (1969).

2 Martin, J. R. \& Perun, T. J. Studies on the biosynthesis of the erythromycins. 3. Isolation and structure of 5-deoxy-5-oxoerythronolide B, a shunt metabolite of erythromycin biosynthesis. Biochemistry 7, 1728-1733 (1968).

3 Khosla, C., Gokhale, R. S., Jacobsen, J. R. \& Cane, D. E. Tolerance and specificity of polyketide synthases. Annu. Rev. Biochem. 68, 219-253 (1999).

4 Werner, G., Hagenmaier, H., Drautz, H., Baumgartner, A. \& Zahner, H. Metabolic products of microorganisms. 224. Bafilomycins, a new group of macrolide antibiotics. Production, isolation, chemical structure and biological activity. J. Antibiot. 37, 110 117 (1984).

$5 \mathrm{Yu}, \mathrm{Z}$. et al. Bafilomycins produced by an endophytic actinomycete Streptomyces sp. YIM56209. J. Antibiot. 64, 159-162 (2011).

6 Otoguro, K., Nakagawa, A. \& Omura, S. Setamycin, a 16-membered macrolide antibiotic. Identification and nematocidal activity. J. Antibiot. 41, 250-252 (1988).

7 Omura, S., Otoguro, K., Nishikiori, T., Oiwa, R. \& Iwai, Y. Setamycin, a new antibiotic. J. Antibiot. 34, 1253-1256 (1981). 
8 Bowman, E. J., Siebers, A. \& Altendorf, K. Bafilomycins: a class of inhibitors of membrane ATPases from microorganisms, animal cells, and plant cells. Proc. Nat Acad. Sci. USA 85, 7972-7976 (1988).

9 Ueda, J. Y. et al. A new 16-membered tetraene macrolide JBIR-100 from a newly identified Streptomyces species. J. Antibiot. 63, 627-629 (2010).

10 Chikanishi, T., Koike, Y., Washimi, Y., Takeuchi, T. \& Koike, Y. TS155-2 and its manufacturing method. Japanese Unexamined Patent Application Publication No. P2000-302782A. (2000).
11 Laakso, J. A., Mocek, U. M., Van Dun, J., Wouters, W. \& Janicot, M. R176502, a new bafilolide metabolite with potent antiproliferative activity from a novel Micromonospora species. J. Antibiot. 56, 909-916 (2003).

12 Werner, G., Hagenmaier, H., Albert, K. \& Kohlshorn, H. The structure of the bafilomycins, a new group of macrolide antibiotics. Tetrahedron Lett. 24, 5193-5196 (1983).

13 Kodani, S., Imoto, A., Mitsutani, A. \& Murakami, M. Isolation and identification of the antialgal compound, harmane (1-methyl- $\beta$-carboline), produced by the algicidal bacterium, Pseudomonas sp. K44-1.. J. Appl. Phycol 9, 109-114 (2002).

Supplementary Information accompanies the paper on The Journal of Antibiotics website (http://www.nature.com/ja) 